\title{
Additive Manufacturing Technology by Furan Sand Mold Using Sintered Artificial Sand Coated with Solid Catalyst*
}

\author{
Yasuhiro Nagai ${ }^{1}$, Kosuke Takeshita ${ }^{1}$ and Toshimitsu Okane ${ }^{2}$ \\ ${ }^{1}$ Gunei Chemical Industry Co., Ltd., Takasaki 370-0032, Japan \\ ${ }^{2}$ National Institute of Advanced Industrial Science and Technology (AIST), Tsukuba 305-8564, Japan
}

In recent years, casting molds made by additive manufacturing (AM) are increasingly applied to build prototypes and small quantity casting product. Devices and materials have been developed for accelerating the molding speed to achieve mass production using AM technology. Conventional AM molding methods using furan type hardening system adopt a combination of a liquid catalyst and binder. The sand wet by the liquid catalyst makes it difficult to increase the molding speed and apply artificial sands which have excellent refractoriness to the sand molding using AM technology.

This study developed a solid catalyst coated sand to improve the flowability of the sand and catalyst and to increase the binder hardening rate. The solid catalyst coated sand was made by covering sintered artificial sand with the solid catalyst of meta-xylene sulfonic acid after covering with the fine powder of anhydrous magnesium sulfate.

First, this study confirmed that the solid catalyst coated sand has good fluidity in fluidity tests. The reduction of the surface tension by the bonding of the powder anhydrous magnesium sulfate and the sulfate of the solid catalyst resulted in the dry state of the solid catalyst sand. Consequently, the catalyst sand showed good fluidity.

Secondly, in mold hardening tests, the solid catalyst coated sand hardened the mold quicker than conventional method. During the hardening reaction of the binder, water generated when furfuryl alcohols were bonded to each other was converted into a hydrate by anhydrous magnesium sulfate and absorbed. As a result, the reaction rate greatly improved compared with conventional methods that only release water outside the system.

Molds using sand additive manufacturing have been used for a long time, but the molding speed and size needs to be improved in order to apply high refractory granular material.

Finally, the ability to mold with this hardening system was tested with the AM molding apparatus using the binder jetting. The results of evaluating the characteristics of the mold showed that it has low thermal expansion and the unhardened part of the solid catalyst coated sand could be reused. [doi:10.2320/matertrans.F-M2020801]

(Received June 24, 2019; Accepted January 8, 2020; Published March 25, 2020)

Keywords: additive manufacturing technology, furfurylalchol, xylene sulfonic acid, magnesium sulfate, sintered artificial sand

\section{Introduction}

In recent years, additive manufacturing (AM) technology of sand is increasingly being applied to build prototypes and small-lot castings. The development of mass production processes applying sophisticated additive manufacturing and casting technologies is expected to enhance the potentials of all castings, since AM technology and casting technologies are able to realize more complicated internal structures and thin-walled lightweight castings through better cavity precision.

However, in the case of sand additive manufacturing (hereafter referred to as 3D AM) methods, which are already being applied practically, the sand is kneaded with liquid catalyst (made by dissolving sulfuric acid or sulfonic acid in water) and refractory particles. For this reason, only sand such as irregularly-shaped silica sand with large specific surface area can be smoothly recoated, while artificial spherical sand with small specific surface area cannot be recoated due to the cohesion between the sand particles generated by the surface tension of the water used as a solvent for dissolving the liquid catalyst. However, it is possible to reduce this cohesion, and recoat sand smoothly by using only sintered artificial spherical sand with irregularities on the surface, and a small amount of liquid catalyst.

*This Paper was Originally Published in Japanese in J. JFS 90 (2018) 280

285. Fig. 5, Fig. 7, Fig. 9, Table 1-Table 3 were slightly changed.
Artificial spherical sand containing alumina or mullite has a small thermal expansion coefficient and high refractoriness. Since there is almost no volumetric expansion due to the heat of molten metal during pouring (when casting melt into the mold), high-precision castings can be obtained. ${ }^{1)}$ Therefore, in the case of silica sand, because silica sand undergoes phase transition at $573^{\circ} \mathrm{C}$ from the heat generated during pouring, the volume of the mold expands. At this time, fine cracks are generated in the mold, which easily leads to baining defect caused by the penetration of the molten metal into the mold. ${ }^{2)}$ From the viewpoint of casting quality, it is thus preferable to use spherical artificial sand than silica sand. However, artificial spherical sand also has a drawback; it has a very small specific surface area due to its spherical shape, and this causes the sand particles to clump together when water with high surface tension is added.

To resolve this problem, in this study, solid catalyst-coated sand was developed by the following procedure. First, an aqueous solution of metaxylene sulfonic acid, which is solid at room temperature, is prepared. This aqueous solution is added to spherically-sintered artificial sand heated to approximately $120^{\circ} \mathrm{C}$. The mixture is then stirred to volatize the solvent. The resultant sand is then cooled to room temperature, and added with anhydrous magnesium sulfate, and mixed.

Most of the water used as the solvent in the prepared solid catalyst-coated sand volatilizes, and the little remaining water and anhydrous magnesium sulfate bond to form a hydrate. 
However, the coated sand is completely dry. Using the coated sand, 3D additive manufacturing is carried out by an ink-jet method which employs furfuryl alcohol mixed with phenol resorcinol as the binder.

The catalytic action of the metaxylene sulfonic acid used as the solid catalyst of the coated sand causes cross-linking of the methylol groups of the furfuryl alcohol by methylene bonding, resulting in the growth of the solid catalyst into a three-dimensional network structure. At this time, large amounts of water are produced, and the binder hardening rate improves if the water can be discharged effectively.

Anhydrous magnesium sulfate changes the state of water generated when it changes into magnesium sulfate hydrate due to the hydration process. ${ }^{3)}$ This hydration process is very fast, resulting in the remarkable increase in the hardening rate of the binder, which contributes to the improvement of the dimensional accuracy of the mold, thereby realizing ultrahigh performance 3D AM molds.

$$
\mathrm{MgSO}_{4}+7 \mathrm{H}_{2} \mathrm{O} \rightarrow \mathrm{MgSO}_{4} \cdot 7 \mathrm{H}_{2} \mathrm{O}
$$

In this study, the fluidity of sand coated with solid catalyst, reaction rate, and thermal expansion coefficient of the mold were measured using a conventional test mold and 3D AM mold. The advantages of using the sintered artificial sand coated with solid catalyst for molding were confirmed by comparison with sand coated using conventional liquid catalyst.

\section{Experimental Method}

\subsection{Hardening system of furan resin binder using sintered artificial sand coater with solid catalyst and evaluation of its characteristics}

\subsubsection{Hardening system of furan resin binder using solid catalyst-coated sand}

Metaxylene sulfonic acid, which is solid at room temperature, was used to prepare the solid catalyst for coating the surface of sintered artificial sand. As the binder to harden the sand during the ink-jetting process, furfuryl alcohol based solution was used. Metaxylene sulfonic acid $\left[\left(\mathrm{CH}_{3}\right)_{2}\left(\mathrm{C}_{6} \mathrm{H}_{3}\right) \mathrm{SO}_{3} \mathrm{H}\right]$ has a melting point of $64^{\circ} \mathrm{C}$ and is a solid at room temperature of $20^{\circ} \mathrm{C}$. It can thus be used to harden furfuryl alcohol-based binders at room temperature.

Furfuryl alcohol $\left[\mathrm{C}_{5} \mathrm{H}_{6} \mathrm{O}_{2}\right]$ has a high boiling point of $171^{\circ} \mathrm{C}$ and a low surface tension of $38.0 \mathrm{mN} / \mathrm{m}$, ${ }^{4}$ and is easily polymerized by solid acid catalysts. In this study, furfuryl alcohol was mixed with resorcinol and N-(2aminoethyl) 3-aminopropylmethyldimethoxysilane as the binder in the $3 \mathrm{D}$ AM process. Resorcinol $\left[\mathrm{C}_{6} \mathrm{H}_{6} \mathrm{O}_{2}\right]$ is a type of benzenediol with two hydroxyl groups in the benzene ring, and activates the hardening reaction of furfuryl alcohol. On the other hand, $\mathrm{N}$-(2-Aminoethyl) 3-aminopropylmethyldimethoxysilane $\left[\mathrm{H}_{2} \mathrm{NC}_{2} \mathrm{H}_{4} \mathrm{NHC}_{3} \mathrm{H}_{6} \mathrm{SiCH}_{3}\left(\mathrm{OCH}_{3}\right)_{2}\right]$ is a type of silane coupling agent which causes chemical bonding ${ }^{5)}$ between the sand and the cured binder, and is effective for improving mold strength.

In the hardening reaction of this system, as shown in Fig. 1, the $\mathrm{O}$ atom of the methylol group $\left(-\mathrm{CH}_{2} \mathrm{OH}\right)$ at the 2-position of the furan ring of the furfuryl alcohol attracts the proton $\left(\mathrm{H}^{+}\right)$present in the acidic area, resulting in a positive

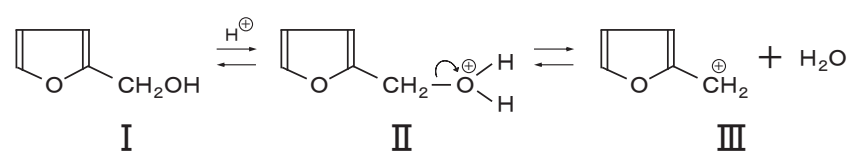

Fig. 1 Generation of carbocation in acidic region.

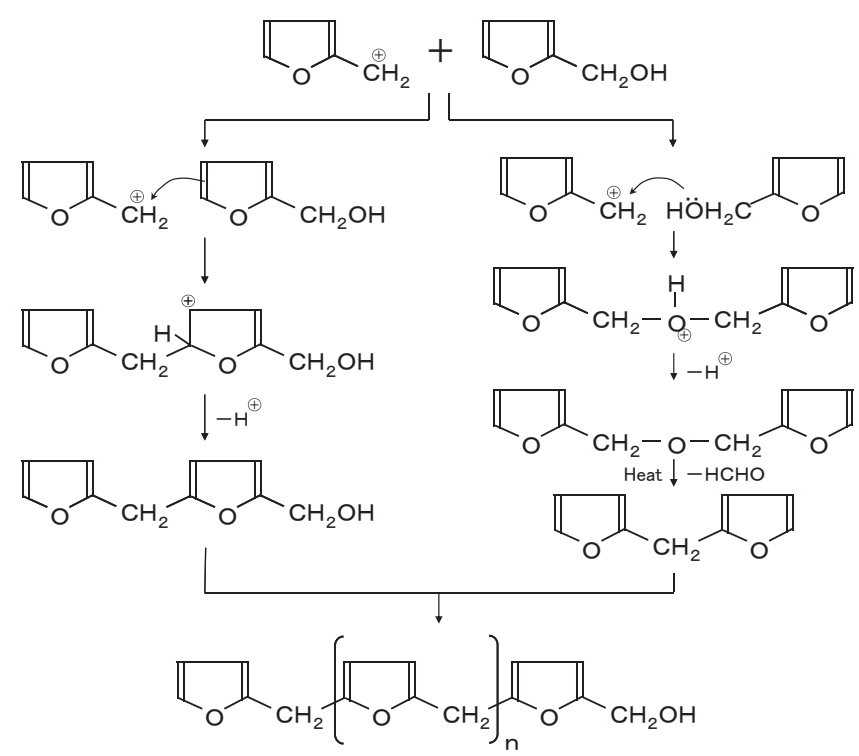

Fig. 2 Methylene bonding process.

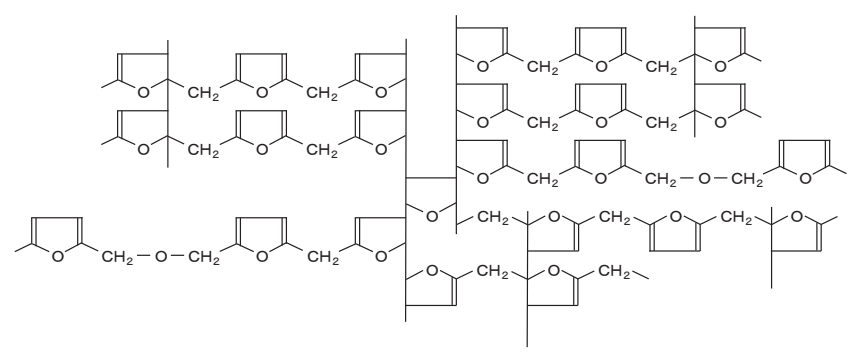

Fig. 3 Three-dimensional crosslinking structure.

charge. Next, the bond between $\mathrm{C}$ and $\mathrm{O}$ breaks, resulting in the formation of carbocation. ${ }^{6)}$ This carbocation is in an electron deficient state, and chain reaction occurs one after another in search of electrons, as shown in Fig. 2. Polymerization progresses due to the bonding of the methylene groups by the hydrogen at the 5-position of the furan ring, dehydration, and then the bonding of the methylene groups due to condensation. Next, as shown in Fig. 3, the formation of a levulinic acid structure by the cleavage of the furan ring progresses rapidly, growing into a three-dimensional cross-linked structure. ${ }^{6}$ )

\subsubsection{Preparation of solid catalyst-coated sand}

For use as additive manufacturing sand, sintered artificial sand (average particle size $106 \mu \mathrm{m}$ ) was heated to approximately $120^{\circ} \mathrm{C}$. The heated sand was then added with 60 mass $\%$ metaxylene sulfonic acid aqueous solution by $0.3 \mathrm{mass} \%$, and the mixture was stirred for $10 \mathrm{~min}$.

After stirring for $10 \mathrm{~min}$, when the sand temperature reached approximately $80^{\circ} \mathrm{C}, 0.3$ mass $\%$ anhydrous magnesium sulfate was added, and the mixture was continuously stirred until the sand temperature reached approximately $25^{\circ} \mathrm{C}$ to obtain the solid catalyst-coated sand. 


\subsubsection{Preparation of inkjet binder}

Based on the specifications of the ink jet head, the physical properties necessary for the inkjet binder were; surface tension of 25.0 to $40.0 \mathrm{mN} / \mathrm{m}^{-1}$ at $20^{\circ} \mathrm{C}$, viscosity 6 to $15 \mathrm{mPa} / \mathrm{s}$, and density of $0.5 \times 10^{3}$ to $1.5 \times 10^{3} \mathrm{~kg} / \mathrm{m}^{-3}$.

From the above physical properties, a solution containing 90 mass \% furfuryl alcohol with a surface tension of 38.0 $\mathrm{mN} / \mathrm{m}^{-1}$ at $20^{\circ} \mathrm{C}$ and 10 mass $\%$ resorcinol for improving the heat resistance and hardening characteristics, was prepared, and the ink-jet binder was prepared by adding N-(2aminoethyl) 3-aminopropylmethyldimethoxysilane to this solution by 0.3 mass \% for improving the adhesion with the additive manufacturing sand.

\subsubsection{Fluidity tests of solid catalyst-coated sand}

The fluidity of the sand was evaluated using a slump cone. First, a cup called slump cone (size: opening $50 \mathrm{~mm} \times$ height $80 \mathrm{~mm} \times$ bottom $40 \mathrm{~mm}$ ) shown in Fig. 4 was filled with sand, a plate was placed over the opening of the cup and turned over, and the slump cone was pulled up vertically from the plate. Next, the spread diameter of the test sand was measured, and the ratio of this diameter to that of the slump cone was calculated. ${ }^{7,8)}$ The clumping state of the sand was observed.

Table 1 shows the test sand and those for comparison used for the experiments in this study. The test sand was solid catalyst-coated sand prepared as described in section 2.1.2. The sand used for comparison was a non-catalytic sintered artificial sand with average particle diameter of $106 \mu \mathrm{m}$, added with 60 mass $\%$ metaxylene sulfonic acid aqueous

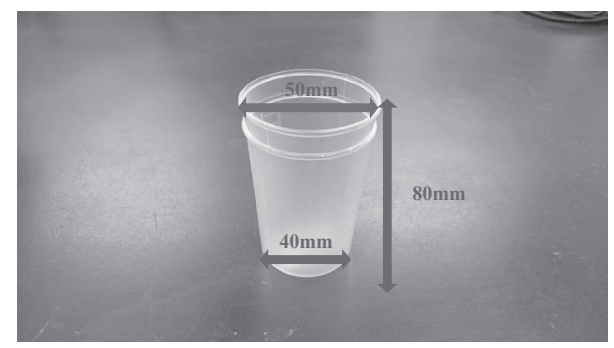

Fig. 4 Slump cone. solution. The comparative sand was also added with aqueous solution by 0.2 mass $\%$ and 0.3 mass $\%$, respectively.

\subsubsection{Mold strength and expression rate test}

In order to evaluate the mold strength and expression rate, kneading sand was put into a wooden pattern to prepare a test mold with a size of $50 \varphi \times 50 \mathrm{~mm}$. The compressive strength of the mold was measured after $1 \mathrm{~h}, 2 \mathrm{~h}, 3 \mathrm{~h}$, and $12 \mathrm{~h}$, respectively at room temperature $25^{\circ} \mathrm{C}$ and relative humidity of $50 \%$ according to JACT test method HM-1 (compression strength test method). $\left.{ }^{9}\right)$

As a test mold, solid catalyst coated sand added 2.0 mass $\%$ of the ink-jet binder was used at the room temperature of $25^{\circ} \mathrm{C}$ and relative humidity of $50 \%$.

As for the comparative sand, silica sand and sintered artificial sand with average particle diameter of $106 \mu \mathrm{m}$, added with 60 mass $\%$ metaxylene sulfonic acid aqueous solution at the room temperature of $25^{\circ} \mathrm{C}$ and relative humidity of $40 \%$, was used. This was added with aqueous solution by 0.2 mass $\%$ and 0.3 mass $\%$ to prepare two types of comparative sands. Finally, ink-jet binder was added by 2.0 mass $\%$.

\subsection{Evaluation of characteristics of 3D additive manu- facturing mold \\ 2.2.1 Moldability and thermal expansion rate}

$3 \mathrm{D}$ additive manufacturing at a pitch of $280 \mu \mathrm{m}$ using an ink-jet of binder was performed. The moldability was confirmed and thermal expansion coefficient of the mold was evaluated. A cylindrical test mold of $30 \varphi \times 50 \mathrm{~mm}$ was made by additive manufacturing in the $\mathrm{X}, \mathrm{Y}$, and $\mathrm{Z}$ axis directions, respectively.

The thermal expansion coefficient of the test mold was measured for $5 \mathrm{~min}$ at the temperature of $1000^{\circ} \mathrm{C}$, using the JACT test method M-2 (rapid thermal expansion measurement method in the thermal expansion tests). ${ }^{10)}$

As a test mold, the additive manufacturing by the furan sand mold using sintered artificial sand coated with 2.0 mass $\%$ of the ink-jet binder.

As a comparative mold, the additive laminated manufacturing mold was used. Silica sand and sintered artificial sand

Table 1 Comparison of test and comparative materials.

\begin{tabular}{|l|c|c|c|}
\hline & Test material & Comparative material 1 & Comparative material 2 \\
\hline Sand & Sintered artificial sand & Sintered artificial sand & Sintered artificial sand \\
\hline Catalyst (mass\%) & 0.18 & 0.2 & 0.3 \\
\hline Furan (mass\%) & 2.0 & 2.0 & 2.0 \\
\hline Hardener & Solid metaxylene & & Metaxylene sulfonic \\
& sulfonic acid, & Metaxylene sulfonic & acid solution \\
State of sand & anhydrous magnesium & acid solution & Wet \\
\hline
\end{tabular}


with an average particle diameter of $106 \mu \mathrm{m}$ added with 60 mass $\%$ aqueous solution of meta-xylene sulfonic acid was prepared. The aqueous solution was added $0.2 \mathrm{mass} \%$ to test sand. The additive manufacturing was carried out for the ink-jet binder of 2.0 mass $\%$.

\subsubsection{Evaluation of reusability of unhardened solid catalyst-coated sand}

In the AM process by binder ink-jetting, large amounts of unhardened sand are generated in places where no ink-jetting is carried out. Reusing this unhardened sand is very costeffective. It seems that the change in the catalytic activity of the solid catalyst-coated sand with time is less than that of the liquid catalyst. For this reason, the reusability of solid catalyst-coated sand was evaluated. For unhardened solid catalyst-coated sand after the 3D AM process, the mold strength test was carry out using the wooden pattern mold after $7 \mathrm{~d}$ at the room temperature of $25^{\circ} \mathrm{C}$ and relative humidity of $50 \%$.

After the binder was added to the solid catalyst-coated sand by 2.0 mass $\%$, the coated sand was put into a $50 \varphi \times$ $50 \mathrm{~mm}$ wooden pattern for preparing the test mold. The compressive strength of this mold was measured after $1 \mathrm{~h}$, $2 \mathrm{~h}, 3 \mathrm{~h}$, and $12 \mathrm{~h}$, respectively. The measured compressive strength of the unhardened solid catalyst-coated sand mold was compared with that of unused solid catalyst-coated sand.

\section{Experiment Results and Discussion}

\subsection{Fluidity of solid catalyst-coated sand}

Figure 5 shows the fluidity test results of various test sand. The fluidity of solid catalyst-coated sand was the same as that of uncoated sintered artificial sand. On the other hand, when liquid catalyst was added to sintered artificial sand, cohesion between the sand and catalyst occurred due to the decrease in fluidity. Comparison of the addition of liquid catalyst by 0.2 mass $\%$ and by 0.3 mass $\%$ clarified that fluidity decreases and cohesion increases when more liquid catalyst is added.

Moreover, mixing sintered artificial sand and liquid catalyst for the AM process was found to cause the clumping of the sand due to the high surface tension of the water contained in the liquid catalyst. The surface tension can be expressed by Young's equation ${ }^{11)}$ as shown in Fig. 6.

As for the solid catalyst-coated sand, water with high surface tension is evaporated beforehand when preparing the

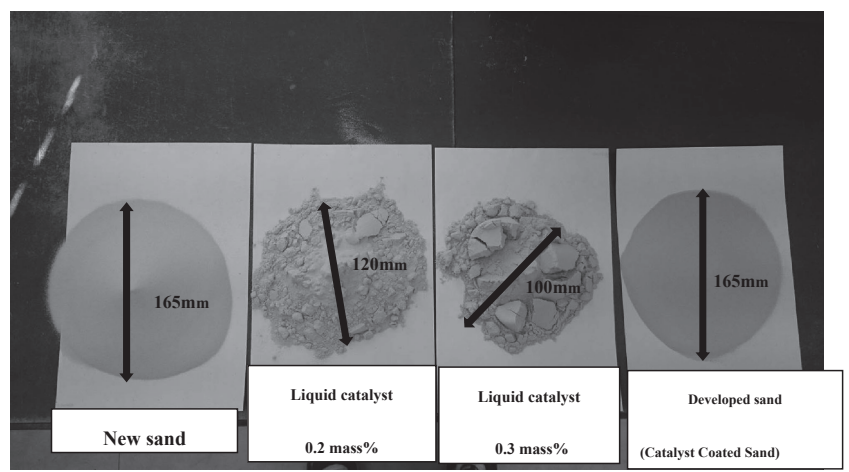

Fig. 5 Comparison of fluidities using slump cone. (a) Sintered artificial sand, (b) Binder mixed with sintered artificial sand, (c) Binder mixed with sintered artificial sand, (d) Catalyst coated-sand.

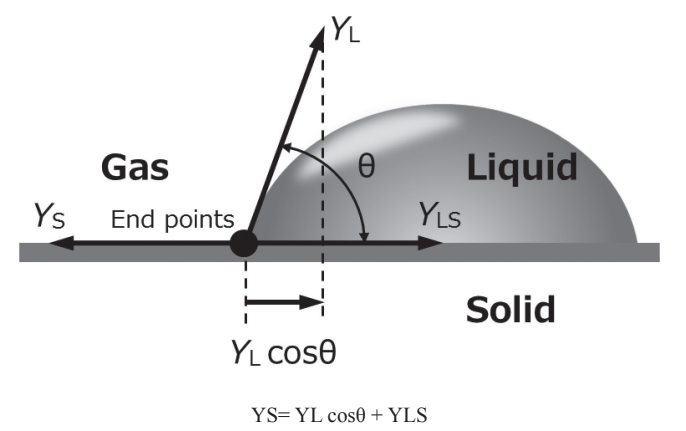

Fig. 6 Relationship between contact angle and surface tension.

solid-state catalyst. Moreover, anhydrous magnesium sulfate fine powder is used to cover the surface of the solid catalyst to lower the surface tension of the water, so that it has the same fluidity as new sand. This is thought to be the factor for realizing the same fluidity.

These results show that solid catalyst-coated sand has excellent fluidity, enables the AM process to be carried out with artificial sand, contributes to mold density improvement, accelerates molding speed, and also has excellent moldability.

\subsection{Mold strength expression}

Figure 7 shows the results of the mold strength expression test. The compressive strength of the test mold after $12 \mathrm{~h}$ was approximately $8 \mathrm{MPa}$. On the other hand, that of the comparative mold after $12 \mathrm{~h}$ was approximately 6 to $8 \mathrm{MPa}$, confirming that compressive strength tends to increase with the increase in the amount of $60 \%$ metaxylene sulfonic acid aqueous solution added as the hardening catalyst.

When the conventional process is prepared by a comparative material, the mold strength can be improved by adding sufficient catalyst to the hardening binder. On the other hand, as shown in the sand fluidity test results, increasing the amount of liquid catalyst added reduces the fluidity of the AM sand and increases cohesiveness. As described below in the section on moldability, the mixture of sintered artificial sand and liquid catalyst makes the AM uniform additive manufacturing of sand difficult due to the increase in the amount of catalyst used. The results of comparing compressive strength after $1 \mathrm{~h}, 2 \mathrm{~h}$ and $3 \mathrm{~h}$ show that molds can be built quickly in $1 \mathrm{~h}$ to $2 \mathrm{~h}$ using solid catalyst, and strength expression is also fast.

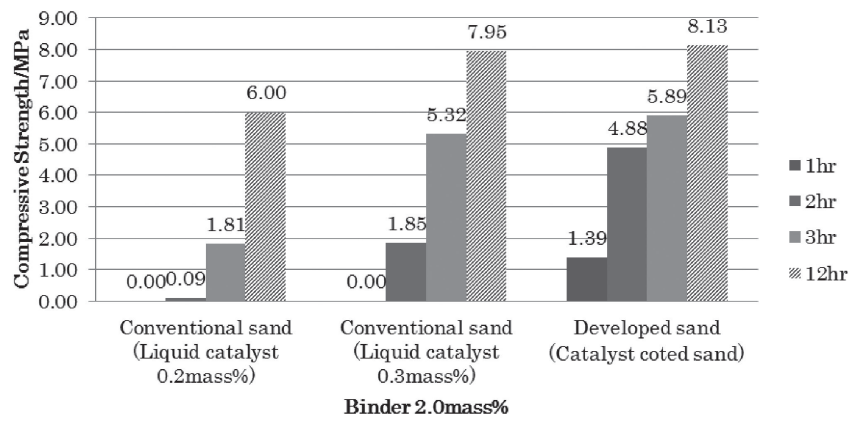

Fig. 7 Compressive strength of catalyst sand. 
On the other hand, from the results of the conventional process using comparative materials, with the mixing process of sintered artificial sand and liquid catalyst, increasing the amount of liquid catalyst results in different mold strengths after 2 to $3 \mathrm{~h}$, which accelerates hardening. However, after $1 \mathrm{~h}$, there is more or less no strength expression, and the amount of liquid catalyst which can be added is limited as described above. From these findings, solid catalyst-coated sand has a high initial hardening speed, which is thought to contribute to accelerating the molding speed and enhancing the shape accuracy of the mold. The reason for this difference may be as follows. In the case of the liquid catalyst, after the sand is mixed with the liquid catalyst, it is then mixed with the binder, and the hardening reaction of the binder progresses. At this time, water generated during the hardening reaction is discharged outside the mold.

On the other hand, in the case of the solid catalyst-coated sand, the sand is coated with metaxylene sulfonic acid, and its catalytic activity causes the hardening of the ink-jet binder to progress. At this time, large amounts of water are generated, and the hardening rate improves if the water can be discharged effectively.

When added with water, anhydrous magnesium sulfate $\left[\mathrm{MgSO}_{4}\right]$ changes into $1,2,4,5,6,7,12$ hydrates, but the most easily formed is heptahydrate.

$$
\mathrm{MgSO}_{4}+7 \mathrm{H}_{2} \mathrm{O} \rightarrow \mathrm{MgSO}_{4} \cdot 7 \mathrm{H}_{2} \mathrm{O}
$$

This hydration process is thought to result in a very high hardening rate. The hydrates rapidly absorb water generated during the hardening of the binder, resulting in a remarkable increase in the hardening rate of the binder.

\subsection{Moldability and thermal expansion rate of 3D AM mold}

Figure 8 shows the AM mold using solid catalyst-coated sand and ink-jet binder. Satisfactory moldability was observed, and the steps by the AM process appeared more clearly. In the case of the comparative mold made of artificial sand and liquid catalyst, although moldability was satisfactory with the addition of liquid catalyst by 0.2 mass $\%$, poor fluidity of sand and coating failure occurred due to the sand cohesion.

Although moldability largely depends on the structure of the recoater of the AM machine, when liquid catalyst is used, increasing the amount of liquid catalyst added decreases moldability.

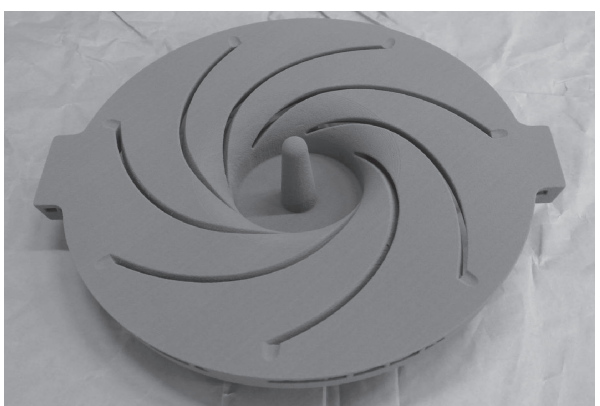

Fig. 8 Photos of sand mold AM technology.

Table 2 shows the test results of the thermal expansion coefficient for the AM and comparative molds. In the case of sintered artificial sand, both the mold of solid catalyst coated sand and that of liquid catalyst mixture had more or less the same low thermal expansion coefficient. However, with the mixture of silica sand and liquid catalyst, the mold had high thermal expansion coefficient. This indicates that the thermal expansion of the mold depends on the type of sand used as shown in Table 3. Especially in the case of silica sand, phase transition occurs at $573^{\circ} \mathrm{C}$ and the mold volume expands. In contrast, the sintered artificial sand had a low coefficient of thermal expansion.

\subsection{Reusability of unhardened solid catalyst-coated sand}

Figure 9 shows the results of mold strength expression tests for unhardened solid catalyst-coated sand and unused solid catalyst-coated sand, seven days after the 3D AM process. Both molds showed similar strength expression and it was confirmed that the unhardened solid catalyst-coated sand can be reused.

\section{Conclusions}

The following results were obtained in this study.

(1) Solid catalyst-coated sand coated with metaxylene sulfonic acid and anhydrous magnesium sulfate can be used for the AM process in a dry state with good fluidity, as a result of the reduction in the surface tension due to the effects of the fine anhydrous magnesium sulfate powder.

Table 2 Thermal expansion coefficient.

\begin{tabular}{|c|c|c|c|}
\hline & Conventional sand 1 & Conventional sand 2 & $\begin{array}{c}\text { Developed sand } \\
\text { (Catalyst-coated sand) }\end{array}$ \\
\hline Sand & Silica sand & Sintered artificial sand & Sintered artificial sand \\
\hline X-axis(mass\%) & 1.50 & 0.11 & 0.10 \\
\hline Y-axis(mass\%) & 1.51 & 0.10 & 0.10 \\
\hline Z-axis(mass\%) & 1.51 & 0.11 & 0.11 \\
\hline
\end{tabular}


Table 3 Refractory particles.

\begin{tabular}{|c|c|c|}
\hline Sand & Silica sand & Sintered artificial sand \\
\hline Composition & $\mathrm{SiO}_{2}$ & $\mathrm{Al}_{2} \mathrm{O}_{3} \cdot \mathrm{SiO}_{2}$ \\
\hline Refractoriness(K) & 2003 & 2098 \\
\hline Linear thermal expansion \\
coefficient(mass $\%)$
\end{tabular}

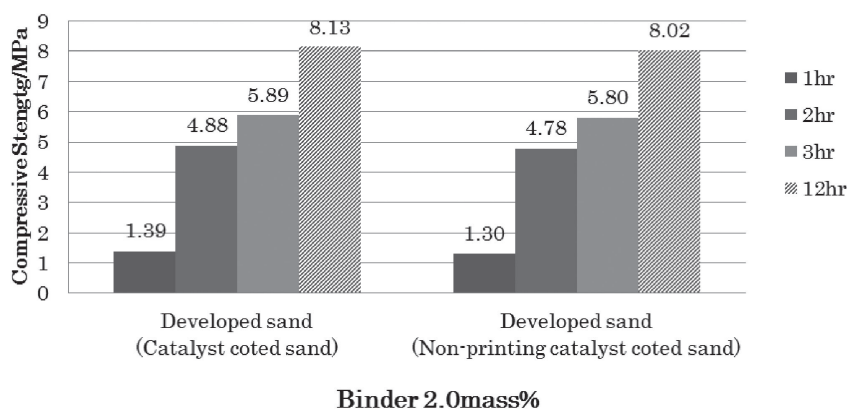

Fig. 9 Reusability test of non-printing solid catalyst coated sand.

Artificial spherical sand can also be used in a dry state with an appropriate amount of catalyst, and exhibits excellent coatability. Furthermore, unhardened sand can also be reused for the 3D AM process.

(2) Water generated during the hardening of the binder in the 3D AM process forms hydrates with anhydrous magnesium sulfate. Unlike the conventional method of discharging the water outside the mold, the hardening rate of the binder greatly increased, and this significantly improved mold strength expression.

(3) The expansion coefficient of the 3D AM mold made of sintered artificial sand was a low value of 0.1 to $0.2 \%$, which is expected to contribute to the production of high quality castings.

\section{Acknowledgements}

This report contains the results of the technological development project "Ultra-Precision 3D Modeling System Technology Development Project" of the Ministry of Economy, Trade and Industry in July 2013.

\section{REFERENCES}

1) Y. Nagai: Cast Steel and Forged Steel 533 (2010) 49-53.

2) Y. Nagai: Powder Technology 6(11) (2014) 22-26.

3) Patent Publication No. 53-119724: Method for producing watersoluble casting mold.

4) Patent No. 5699252: Method for producing exfoliated graphite and exfoliated graphite dispersion, and exfoliated graphite, exfoliated graphite dispersion and exfoliated graphite-resin composite material.

5) Toshiba Silicone Co., Ltd.: New Silicone and Its Application, (Toshiba Silicone Co., Ltd., 1994) p. 36.

6) Japan Foundry Society Inc.: 4th Edition Mold Molding Method, (Japan Foundry Society Inc., 1996) pp. 130-146.

7) K. Hayashi, Y. Fukuda, S. Tomita, T. Komai, Y. Urushita and T. Kobayashi: Proceedings of the Japan Foundry Society 161, (2012) 92.

8) Y. Nagai, K. Takeshita, Y. Hatori, T. Okane, K. Imamura and Y. Oba: Proceedings of Japan Foundry Society 166th Annual National Conference Meeting Lecture Series, (2015) 15.

9) Japan Small Business Corporation Edition: Testing Methods for Molds and Mold Materials, (Japan Small Business Corporation Information and Technology Department, 1999) pp. 76-78.

10) Japan Small Business Corporation Edition: Testing Methods for Molds and Mold Materials, (Japan Small Business Corporation Information and Technology Department, 1999) pp. 46-53.

11) H. Yoshino: Learning Approximately Material Science from Water, (Osaka City University, 2015) pp. 57-58. 